\title{
Preoperative cognitive assessment: development of a self-administered screening tool and normative data for an elderly population
}

\author{
Nicolai Goettel, MD ${ }^{1,2 *}$, Raphael Monsch, MMed ${ }^{1}$, Alessandra Thomann, MSc ${ }^{1,4}$, Manfred Berres, $\mathrm{PhD}^{3}$, Luzius Steiner, MD, PhD ${ }^{1,2}$
}

1'Department of Anesthesia, Surgical Intensive Care, Prehospital Emergency Medicine and Pain Therapy, University Hospital Basel, Switzerland; ${ }^{2}$ Department of Clinical Research, University of Basel, Switzerland; ${ }^{3}$ Memory Clinic, University Center for Medicine of Aging Basel, Felix Platter Hospital Basel, Switzerland; 4Department of Mathematics and Technology, University of Applied Sciences Koblenz, Germany

Background: Pre-existing cognitive impairment in surgical patients is one of the leading risk factors for adverse cognitive outcomes such as postoperative delirium and postoperative cognitive dysfunction. We developed a self-administered tablet computer application to assess the individual risk for adverse postoperative cognitive outcomes. This prospective observational cross-sectional study aimed to establish normative data for this test tool.

\section{Setting: Swiss University hospital.}

Methods: Healthy volunteers aged $\geq 65$ years were administered the Mini-Menta State Examination (MMSE), Geriatric Depression Scale (GDS), and Consortium to Establish a Registry for Alzheimer's Disease-Neuropsychological Assessment Battery (CERAD-NAB) to assess cognitive health. All subjects completed the tablet computer application CogCheck consisting of a test battery assessing six cognitive domains. The primary outcome measure was the test performance. Regression models were built for each cognitive domain score with the covariates age, gender, and education in cognitively healthy subjects. Demographically-adjusted standard scores (z-scores) were computed for each subtest.

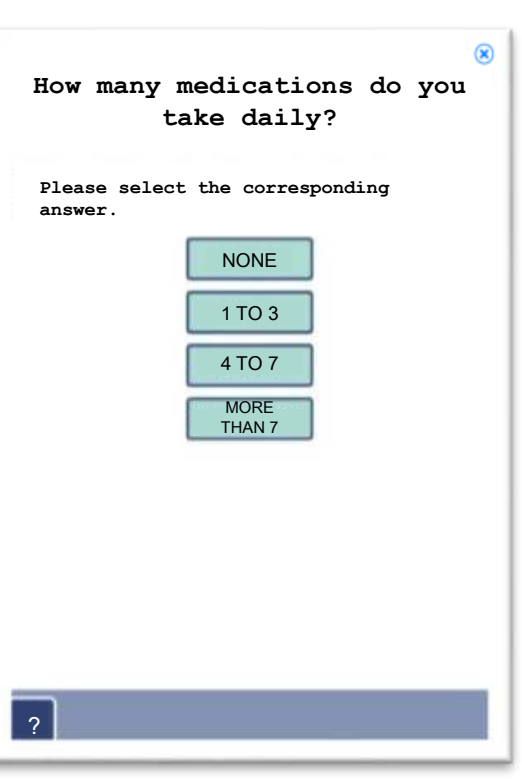

Medication

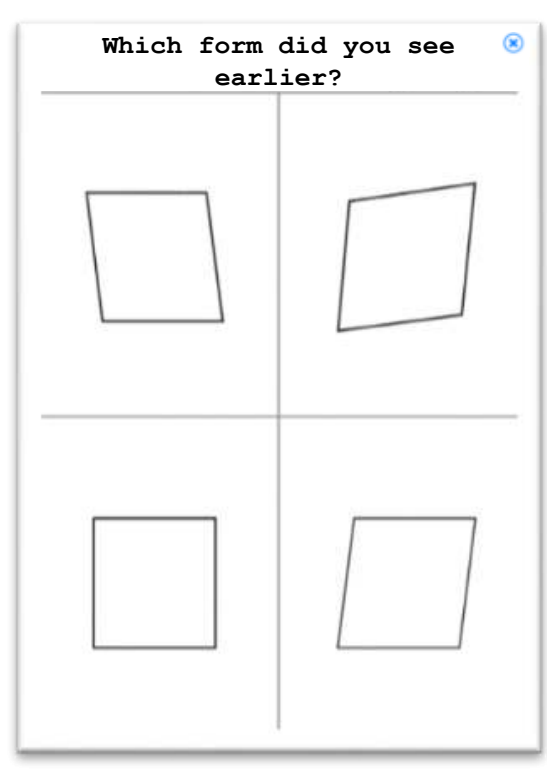

Visual recognition: selection

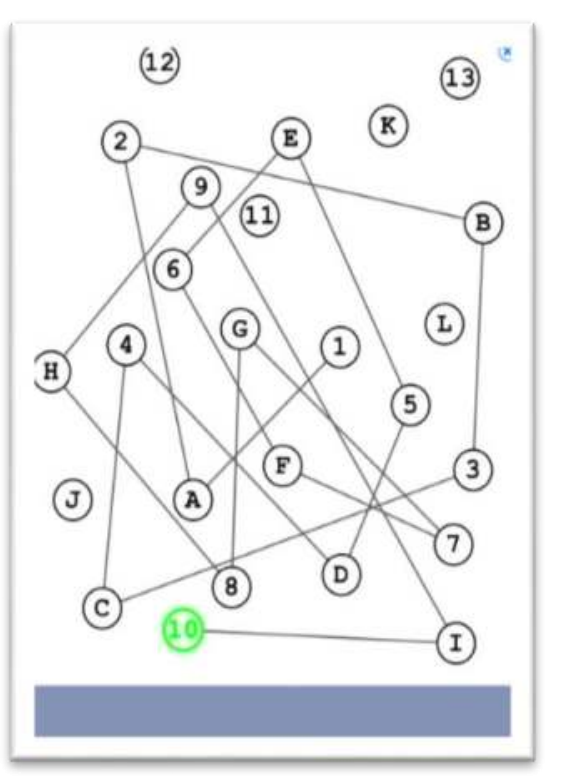

Trail Making Test B
Figure 1 Translated screenshots of the CogCheck application.

\begin{tabular}{|c|c|c|}
\hline & Description of question or task & Cognitive domain \\
\hline \multicolumn{3}{|l|}{ Demographic and medical data } \\
\hline Vision & Use of vision aids & Self-reporting \\
\hline Hearing & Presence of hearing impairment or use of hearing aids & Self-reporting \\
\hline Medication & Entry of the number of daily drugs & Self-reporting \\
\hline Age & Entry of the age in years & Orientation \\
\hline Education & Entry of the education in years & Self-reporting \\
\hline \multirow[b]{2}{*}{ Language } & German indicated as native language & Self-reporting \\
\hline & $\begin{array}{l}\text { If the native language is not German: rating of the } \\
\text { German language skills }\end{array}$ & Self-reporting \\
\hline \multicolumn{3}{|l|}{ Cognitive self-assessment } \\
\hline & $\begin{array}{l}\text { Answering five questions about the ability to cope with } \\
\text { daily situations compared to two years ago: } \\
\text { (1) Memorising new things; } \\
\text { (2) Remembering names; } \\
\text { (3) Multiple simultaneous tasks; } \\
\text { (4) Financial issues; } \\
\text { (5) Remembering appointments }\end{array}$ & Self-reporting \\
\hline \multicolumn{3}{|l|}{ Temporal orientation } \\
\hline Weekday & Entry of the weekday (Monday to Sunday) & Orientation \\
\hline$\overline{\text { Date }}$ & Entry of the day, month and year & Orientation \\
\hline \multicolumn{3}{|c|}{ Automated subtests of cognitive functions } \\
\hline Visual recognition & $\begin{array}{l}\text { 15-item multiple-choice version of the Benton Visual } \\
\text { Retention Test. }\end{array}$ & Visual memory \\
\hline $\begin{array}{l}\text { Picture learning and } \\
\text { recognition }\end{array}$ & $\begin{array}{l}\text { Recognition of } 10 \text { hand-drawings that were shown for } \\
\text { three seconds each among } 30 \text { pictures at the end of } \\
\text { the test. }\end{array}$ & Episodic memory \\
\hline Digit span & $\begin{array}{l}\text { Repetition of an extending series of randomly } \\
\text { presented digits }\end{array}$ & Attention span \\
\hline Spatial span & Repetition of an extending series of blinking blocks & Visuospatial attention \\
\hline Reaction time and attention* & $\begin{array}{l}\text { Tapping on the screen as fast as possible if a star } \\
\text { appears ( } 15 \text { stars out of } 15 \text { other geometric forms) }\end{array}$ & $\begin{array}{l}\text { Reaction time and } \\
\text { attention }\end{array}$ \\
\hline Trail Making Test $\mathbf{A}$ & $\begin{array}{l}\text { Electronic version of the Trail Making Test A, limited in } \\
\text { time }(45 \mathrm{sec})\end{array}$ & Psychomotor speed \\
\hline Trail Making Test $\mathrm{B}$ & $\begin{array}{l}\text { Electronic version of the Trail Making Test B, limited in } \\
\text { time }(60 \mathrm{sec})\end{array}$ & Flexibility \\
\hline
\end{tabular}

Table 1 Content and structure of the CogCheck application. ${ }^{*}$ The reaction time and attention task was discarded from CogCheck.
Results: 283 participants were included in the final analysis. Participants' mean (SD) age was 73.8 (5.2) years, and their average level of education was 13.6 (2.9) years. Mean (SD) MMSE score was 29.2 (0.9) points, GDS score was 0.4 (0.7) points, and CERAD-NAB total score was 98.7 (5.7) points. Older age was associated with poorer performance in the visual recognition task and in Trail Making Test $\mathrm{B}(P<0.05$ after Bonferroni-Holm adjustments).

\begin{tabular}{llllll}
\hline & $\begin{array}{l}\text { All participants } \\
(\mathbf{n}=\mathbf{2 8 3})\end{array}$ & $\begin{array}{l}\mathbf{6 5 - 6 9} \text { years } \\
(\mathbf{n}=\mathbf{6 8})\end{array}$ & $\begin{array}{l}\mathbf{7 0 - 7 4} \text { years } \\
(\mathbf{n}=\mathbf{1 0 2})\end{array}$ & $\begin{array}{l}\mathbf{7 5 - 7 9} \text { years } \\
(\mathbf{n}=\mathbf{6 8})\end{array}$ & $\begin{array}{l}>\mathbf{7 9} \text { years } \\
(\mathbf{n}=\mathbf{4 5})\end{array}$ \\
\hline $\begin{array}{l}\text { Demographics } \\
\text { Age; years }\end{array}$ & $73.8 \pm 5.2$ & $67.6 \pm 1.4$ & $72.2 \pm 1.3$ & $76.5 \pm 1.4$ & $82.6 \pm 2.4$ \\
$\quad$ Female gender & $155(55)$ & $42(62)$ & $58(57)$ & $34(50)$ & $21(47)$ \\
$\quad$ Education; years & $13.6 \pm 2.9$ & $13.2 \pm 2.7$ & $14.0 \pm 2.8$ & $13.7 \pm 3.1$ & $13.3 \pm 2.8$ \\
\hline Medical comorbidities & & & & & \\
$\quad$ Heart disease & $54(19)$ & $5(7)$ & $13(13)$ & $17(25)$ & $19(42)$ \\
Arterial hypertension & $112(40)$ & $20(29)$ & $36(35)$ & $31(46)$ & $25(56)$ \\
Hypercholesterolemia & $60(21)$ & $14(21)$ & $14(14)$ & $18(26)$ & $14(31)$ \\
Diabetes type II & $14(5)$ & $4(6)$ & $6(6)$ & $1(1)$ & $3(7)$ \\
Chronic lung disease & $14(5)$ & $1(1)$ & $3(3)$ & $8(12)$ & $2(4)$ \\
Gastrointestinal disease & $23(8)$ & $4(6)$ & $11(11)$ & $2(3)$ & $6(13)$ \\
Urologic disease & $27(10)$ & $3(4)$ & $8(8)$ & $9(13)$ & $7(16)$ \\
Thyroid diseasee & $30(11)$ & $8(12)$ & $12(12)$ & $7(10)$ & $3(7)$ \\
Arthrosis & $35(12)$ & $8(12)$ & $11(11)$ & $13(19)$ & $3(7)$ \\
Osteoporosis & $34(12)$ & $4(6)$ & $14(14)$ & $10(15)$ & $6(13)$ \\
Chronic pain & $27(10)$ & $5(7)$ & $9(9)$ & $9(13)$ & $4(9)$ \\
History of head trauma & $25(9)$ & $5(7)$ & $11(11)$ & $5(7)$ & $4(9)$ \\
Prior general anesthesia & $239(84)$ & $59(87)$ & $85(83)$ & $56(82)$ & $39(87)$ \\
Regular alcohol consumption & $181(64)$ & $45(66)$ & $61(60)$ & $49(72)$ & $26(58)$ \\
\hline Neuropsychological tests & & & & & \\
MMSE score & $29.2 \pm 0.9$ & $29.4 \pm 0.7$ & $29.3 \pm 0.9$ & $29.0 \pm 0.9$ & $28.9 \pm 1.0$ \\
GDS score & $0.4 \pm 0.7$ & $0.3 \pm 0.8$ & $0.4 \pm 0.7$ & $0.3 \pm 0.6$ & $0.4 \pm 0.7$ \\
CERAD-NAB total score & $98.7 \pm 5.7$ & $97.9 \pm 5.5$ & $98.6 \pm 5.2$ & $99.5 \pm 5.9$ & $99.0 \pm 6.5$ \\
\hline
\end{tabular}

Table 2 Demographic characteristics according to age category.

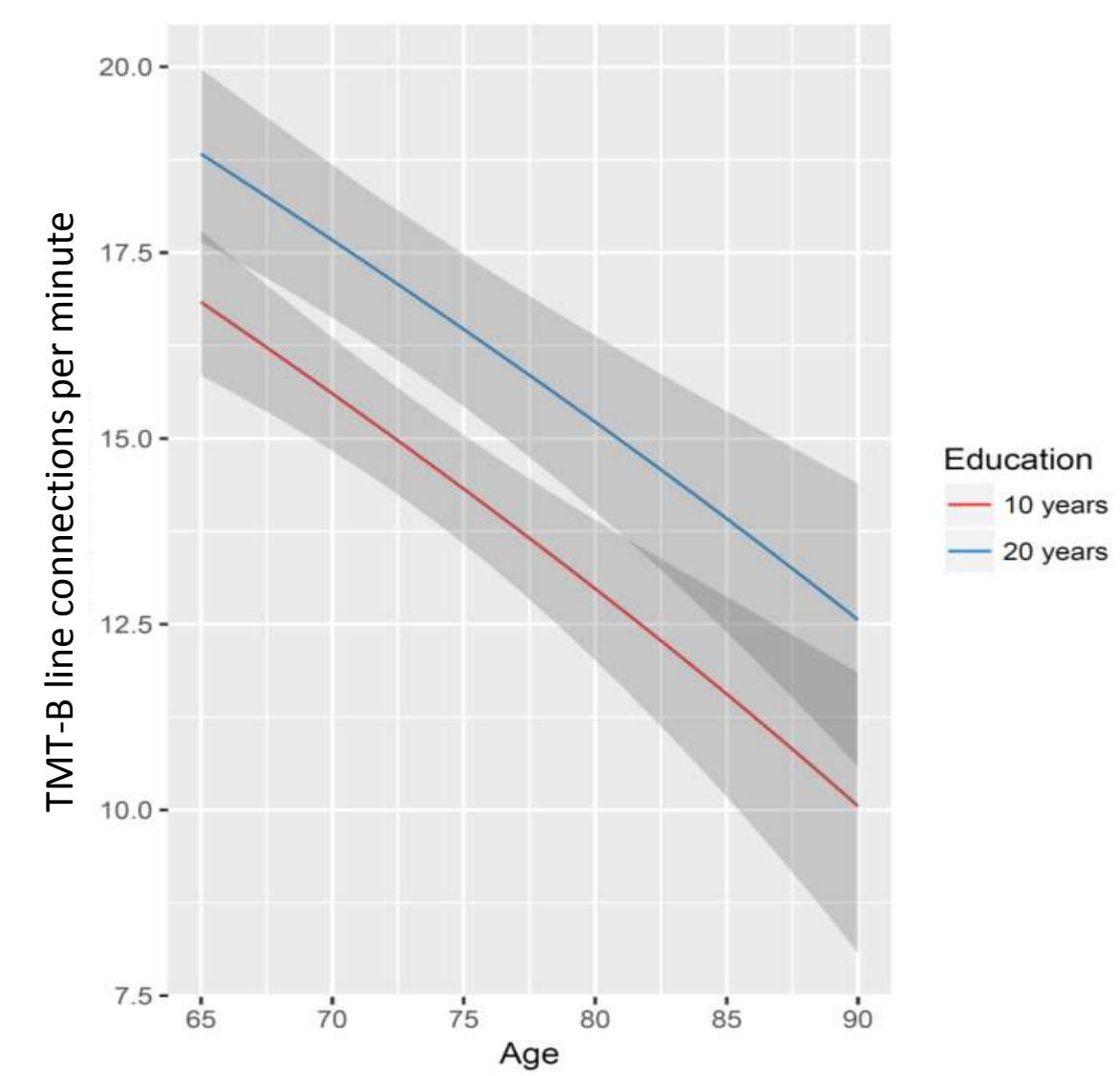

Figure 2 Predicted Trail Making Test $B$ (TMT-B) score with $95 \%$ confidence interval. The ratio of correct line connections per min
measure the accuracy of performance. In this model, older age and lower education were associated with a lower TMT-B score.

A
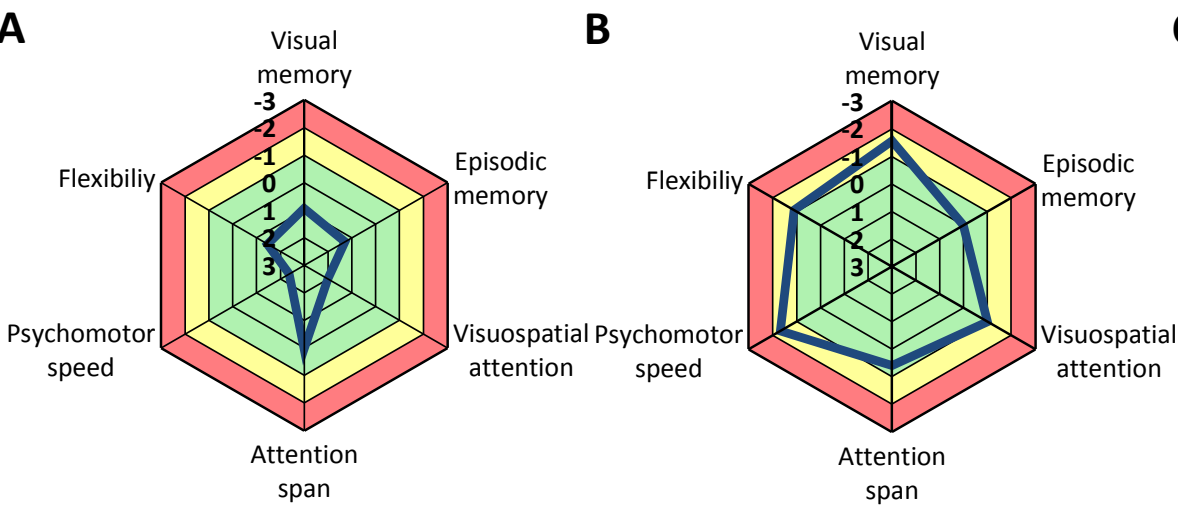

Figure 3 Examples of individual risk profiles originating from RAPACO. The risk for adverse postoperative cognitive outcome is stratified according to the Diagnostic and Statistical Manual of Mental Disorders (DSM-5) criteria of mild and major neurocognitive disorders. Demographically-adjusted (age, gender and education) standard scores (z-scores) in six cognitive domains (visual memory, episodic memory, visuospatial attention, attention span,

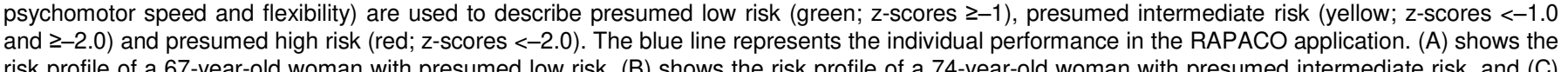
shows the risk profile of a 88 -year-old woman with presumed high risk.
s.tist

Conclusions: This study provides demographically-adjusted normative data for a novel self-administered tablet computer application designed to measure the individual risk for adverse postoperative cognitive outcomes in elderly patients. 